\title{
The Harmonious Interactions of the Dancer and the Body
}

\author{
Brandon Monzon* \\ Communications Generalist, University of Michigan, USA \\ *Corresponding author: Brandon Monzon T, Communications Generalist, University of Michigan, USA
}

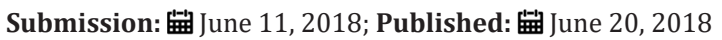

\section{Opinion}

How do dancers efficiently use motion in modern dance to create elegant movement with their instruments? Professor Bill DeYoung is exploring that question. Advances in kinesiology and movement research during the last half-century have enabled DeYoung to develop the Aesthetics of Balance Project (ABP). The goal is to help dancers become more aware of how the human instrument works by developing training tools that enable them to identify specific muscle connections to enhance technical performance. The ABP, which is funded by research grants from U-M's Office of Research and SMTD, comprises two teams. One team is focusing on developing a wearable "inertial measurement unit" (IMU) that provides sound feedback to enable balance training tools for dancers. The other team is developing smart phone delivery of physical therapy exercises for dancers. DeYoung developed the ABP by partnering with physicians, physical therapists, biomechanical engineers, and cinematographers-along with SMTD dance faculty, alumni, and current students.

DeYoung's interest in this area is not surprising; before becoming a dancer, he was a pre-med student. "After my first year I decided I needed to break out because it didn't feel right," he said. "An experience in theatre helped me find dance, and it was a calling fulfilled." It's not unusual for dancers to have an interest in medicine and physical therapy; the synergy between the fields often leads to dual careers. Many SMTD dance alumni obtain doctorates in physical therapy, and former and current students frequently pursue minors or dual majors in the U-M School of Kinesiology. In fact, DeYoung and dance professor Angela Kane coordinated a dance science group that met with physical therapists and doctors in different areas of the University.

For DeYoung, the role of momentum in dance is key, and he uses it as a learning tool in his technique classes. This came up in conversation with Dr. Andrew Haig during a personal visit, which led to an important collaboration. Haig is a physician specialist in physical medicine, a field that treats a wide variety of medical conditions affecting the brain, spinal cord, nerves, bones, joints, ligaments, muscles, and tendons. "My daughter is a dancer, and I happen to care for some dance faculty in my clinic," Haig said. "I saw their brilliance regarding how the human body moves. Dancers need strength, coordination, flexibility, endurance, and grace, which is the last piece missing in so much of our science. Bill and I realized that if we could more scientifically understand the factors that lead to graceful movement, we might impact much more than dance and sports performance."

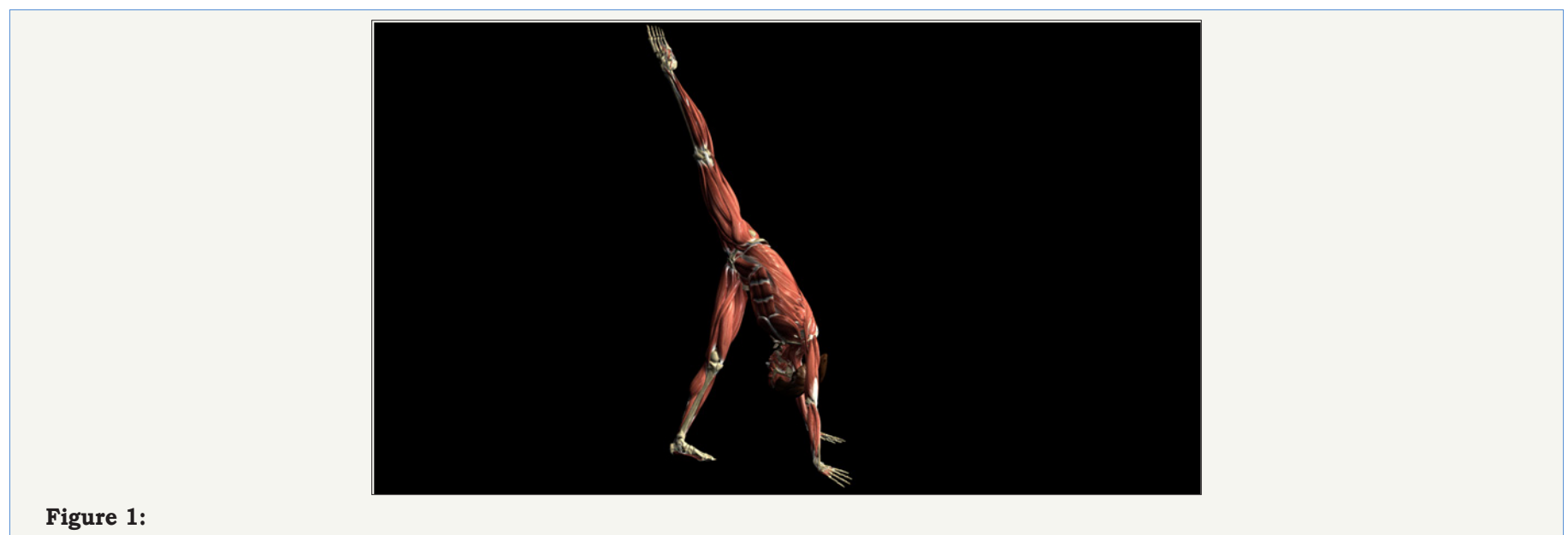


Haig encouraged DeYoung to consider the impact of his research beyond dance. "Falls in the elderly, rehabilitation for stroke victims, daily life for kids with cerebral palsy...all of these situations might be improved if we added that component of movement to our thought processes," said Haig. "When we can capture and teach sophisticated movement, I think we will have developed the tool that radically changes the way we treat people with movement disorders, whether the cause is stroke, brain injury, or nerve disease. That will be huge in my field." In addition to physicians, the ABP also needed the help of engineers. DeYoung first worked with Efren Cruz, an engineering doctoral student with experience in machine learning, to find out how to best quantify and classify the grace and balance that skilled dancers possess (Figure 1).

Then, in September 2015, Antonia Zaferiou, a postdoctoral student in biomechanics from the University of Southern California (USC), joined U-M to learn more about wearable sensors and to develop interactive biofeedback technology that relays mechanics through music. At USC, Zaferiou had begun developing ways to convey mechanical information, specifically the forces between a dancer and the ground, using music. The work was in collaboration with Vangelis Lympouridis, who used IMUs during his doctoral studies to allow flamenco dancers to control their music with their movements. "I met Bill when I started looking to take dance classes in Ann Arbor," said Zaferiou. "We immediately discovered that we had overlapping research interests, so we brainstormed to discover how to best collaborate. The combination of Bill's dance expertise and my biomechanics expertise fused seamlessly, allowing us to embark on developing this innovative technology."

Zaferiou focused the project on measuring the control of the pelvis using a wearable IMU. In this project, the IMU measures how the pelvis is controlled while a dancer moves through space and uses sonification-the use of music to convey data-to help train the dancer. The IMUs have three internal components: an accelerometer that measures how quickly something changes speed and/or direction; a gyroscope that measures how quickly something is rotating or tilting (including direction); and a magnetometer, which measures the direction of magnetic north. Since January 2016, Cruz and Zaferiou have been co-mentoring engineering and kinesiology graduate students with the goal of finding the best way to measure, process, and sonify pelvis motion using an IMU. This "wearable tech" can help dancers understand the process of knowing their bodies, and has also helped DeYoung in his classes. "I like to ask students how we can work harmoniously with the physics of the world we live in, how to understand that gravity works 32 feet per second, squared," said DeYoung. "To be in harmony, to turn, to jump, cuts through all of the techniques our students will learn over four years. I really think it's about helping dancers to attain elegant and harmonious movement."

The other research thrust of the ABP hopes to display those elegant movements, along with physical therapy exercises for dancers, through an innovative delivery method via a smartphone app or eBook.

In December 2015, DeYoung led a team consisting of U-M MedSport physical therapist Kristen Schuyten, professional cinematographer David Blood, producer and dance alumna Ericka Frederick (BFA '92), and staff at U-M's Digital Media Commons in a three-day shoot for this second area of ABP research. The shoot used a 3D anatomical rigging model that synced up with motion capture footage of SMTD dancers. These videos aim to reveal the deeper layers of musculoskeletal structures that need to be engaged for proper balance and execution of the physical therapy exercises.

The videos are a key research and development component for the ABP. Partnering with Jessica Soulliere, digital technologies senior licensing specialist for the Office of Technology Transfer at U-M, DeYoung and Schuyten are working on the beta version of their software. They have had an FDA assessment and are now in the process of meeting with software developers. DeYoung is fully committed to the ABP, and remains passionate about the project. "As an older dancer, I keep learning new things about my instrument, so it's a path that doesn't stop," he said. "Knowing thyself in an embodied way has kept me as enthusiastic as I was when I first began my dance career. We are all curious and follow different threads, but it is always about that sense of asking questions and finding answers."
Creative Commons Attribution 4.0 International License

For possible submissions Click Here

\section{Submit Article}

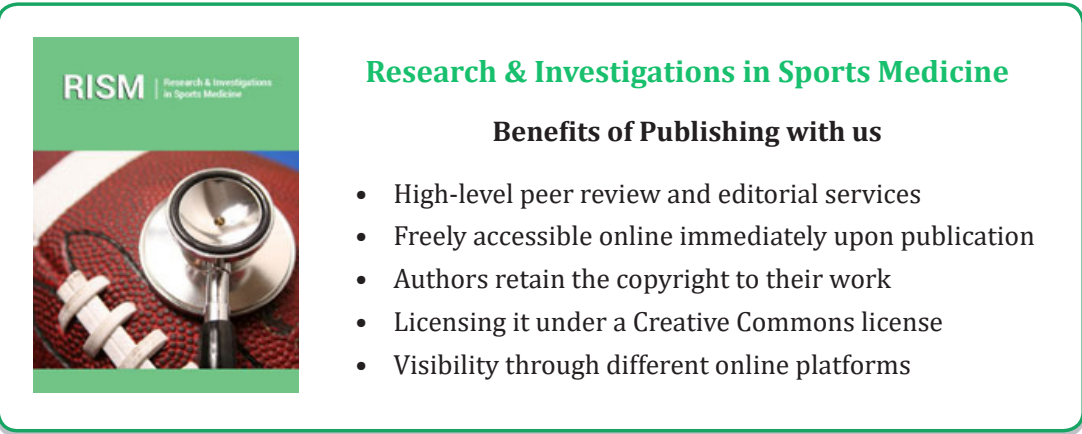

